\title{
Contribuição para o aprimoramento de projeto, construção e operação de reatores UASB aplicados ao tratamento de esgoto sanitário - Parte 2: Tratamento preliminar, bombeamento e distribuição de vazão
}

\section{Contribution for improving the design, construction and operation of UASB reactors treating sewage - Part 2: Preliminary treatment, pumping and influent distribution}

\author{
Data de entrada: \\ 01/08/2018 \\ Data de aprovação: \\ $17 / 09 / 2018$
}

Thiago Bressani Ribeiro / Lívia Cristina da Silva Lobato / Saulo Nonato de Souza / Eduardo Sabino Pegorini / Carlos Augusto de Lemos Chernicharo (*)

DOI: 10.4322/dae.2018.039

\section{Resumo}

A etapa de tratamento preliminar é fundamental para o adequado condicionamento do esgoto antes de sua entrada nos reatores UASB. Nesta Nota Técnica objetiva-se discorrer sobre os principais problemas, suas respectivas origens e os possíveis aprimoramentos associados ao tratamento preliminar, bombeamento e distribuição de vazão nos reatores UASB. Em síntese, um adequado tratamento preliminar influenciará positivamente: i) na manutenção das estruturas de distribuição de vazão e calhas coletoras de efluente, evitando obstruções; ii) na redução da deposição e acúmulo de areia no fundo de reatores UASB; iii) no gerenciamento do lodo, visto que será possível obter um material sólido com menor conteúdo de detritos e areia, e de melhor qualidade estética; iv) no gerenciamento da escuma, sobretudo devido ao fato de que, quando não removidos adequadamente no tratamento preliminar, alguns materiais (p.ex.: plásticos e detritos leves em geral) tendem a flotar no interior do reator e acumular na parte superior do separador trifásico; v) na redução significativa de problemas corriqueiros na operação das unidades de processamento mecanizado de lodo e escuma, como paralisação por obstruções de tubulações, quebra e perda de rendimento de equipamentos por desgaste. Palavras-chave: Desarenador, gradeamento, odor, peneiramento, resíduos do tratamento preliminar

\footnotetext{
Thiago Bressani Ribeiro - Engenheiro Ambiental pela Universidade FUMEC. Mestre em Saneamento, Meio Ambiente e Recursos Hídricos pela UFMG. Doutorando em Saneamento pelas Universidades de Ghent (Bélgica) e UFMG. Membro do INCT ETEs Sustentáveis.

Lívia Cristina da Silva Lobato - Engenheira Civil pela UFMG. Doutora em Saneamento, Meio Ambiente e Recursos Hídricos pela UFMG. Membro do INCT ETEs Sustentáveis.

Saulo Nonato de Souza - Engenheiro Civil pela UFMG. Engenheiro de Operação da Companhia de Saneamento de Minas Gerais (Copasa). Mestrando em Saneamento, Meio Ambiente e Recursos Hídricos pela UFMG.

Eduardo Sabino Pegorini - Engenheiro Agrônomo e Mestre em Ciências do Solo pela UFPR. Engenheiro da Unidade de Gestão de Projetos do KFW na Companhia de Saneamento do Paraná (Sanepar).

Carlos Augusto de Lemos Chernicharo - Engenheiro Civil pela UFMG. Doutor em Engenharia Ambiental pela Universidade de Newcastle upon Tyne - UK. Professor titular do Departamento de Engenharia Sanitária e Ambiental da UFMG. Coordenador do INCT ETEs Sustentáveis. "Endereço para correspondência: Avenida Antônio Carlos 6.627 - Universidade Federal de Minas Gerais - Escola de Engenharia - Departamento de Engenharia Sanitária e Ambiental - Bloco 1. Belo Horizonte, MG. CEP: 31270-901. e-mail: calemosadesa.ufmg.br
} 


\section{Abstract}

The preliminary treatment step is essential for the adequate sewage conditioning prior to UASB reactors. This Technical Note aims to discuss the main problems, their respective origins and the possible improvements associated with the preliminary treatment, pumping and influent distribution to UASB reactors. In summary, an adequate preliminary treatment will positively influence: i) the maintenance of the flow distribution structures and effluent collection system, avoiding obstructions; ii) the reduction of deposition and accumulation of sand at the bottom of UASB reactors; iii) the management of sludge, since it will be possible to obtain a biosolid with lower content of debris and sand, and of better aesthetic quality; iv) the management of scum, mainly due to the fact that, when not properly removed in the preliminary treatment, some materials (e.g. plastics and light debris in general) tend to float inside the reactor and accumulate in the upper part of the three-phase separator; v) the significant reduction of common problems in the operation of sludge and scum processing units, such as stoppage due to pipe obstruction, breakage and loss of equipment performance due to wear. Keywords: Grit chamber, odour, residues of the preliminary treatment, screening, sieving

\section{INTRODUÇÃO}

A etapa de tratamento preliminar (TP) em uma estação de tratamento de esgoto (ETE) é tipicamente composta por grades de barras e desarenadores. O principal papel das unidades que compõem o tratamento preliminar está associado à remoção de sólidos que poderiam comprometer o adequado funcionamento das unidades subsequentes do tratamento (neste caso, dos reatores UASB), sobretudo em virtude de obstruções de tubulações, avarias a equipamentos eletromecânicos, acumulação de areia no interior dos reatores e formação de escuma. Esses problemas usualmente também se estendem para equipamentos e unidades do processamento dos subprodutos do tratamento, como lodo e escuma, requerendo paralisações frequentes, as quais podem variar de simples limpezas e desobstruções até a quebra de equipamentos de manutenção delicada e lenta (p. ex.: centrífugas).

Especificamente quanto às grades, busca-se adotar um espaçamento entre barras que permita uma eficiente remoção de detritos (p. ex.: cabelo, cotonete, absorvente, fio dental, algodão, lenço umedecido, ponta de cigarro, materiais plásticos). Notar que estes detritos não deveriam ser descartados pelos usuários nas instalações sanitárias domiciliares e redes coletoras de esgoto. Quando da utilização de uma sequência de grades (geral- mente duas), adota-se um espaçamento entre barras gradualmente decrescente (grades grosseiras, médias, finas, ultrafinas). A alternativa de gerenciamento do material retido (fase sólida) está associada tipicamente à disposição final em aterros sanitários, eventualmente precedida de uma etapa de remoção de umidade. Para ETEs de pequeno porte, esta disposição final pode ocorrer na própria área da estação, em valas adequadamente preparadas e licenciadas para o recebimento dos rejeitos. Todavia, ressalta-se que as condições técnicas para esta forma de disposição final são similares às de um aterro sanitário, o que pode implicar em excessiva demanda construtiva e operacional para ETEs de pequeno porte. 0 aproveitamento energético do material retido na grade (p.ex.: coprocessamento em fornos de clínquer) ainda é incipiente no Brasil, mas há relatos que indicam um considerável poder calorífico inferior ( $\mathrm{PCl}$ ) e baixo teor de cinzas associados aos resíduos retidos na etapa de gradeamento fino (BORGES, 2014). Adicionalmente, a celulose pode constituir a maior parcela da demanda química de oxigênio (DOO) inerte presente no esgoto, devido ao papel higiênico (RUIKEN et al., 2013), sendo que em alguns países desenvolvidos a sua recuperação já vem sendo realizada em escala piloto/ plena, objetivando o aproveitamento energético, 
incorporação ao asfalto, dentre outros (MARCELIS e WESSELS, 2018).

Em relação aos desarenadores, a depender do porte da ETE, pode-se considerar a utilização de unidades de: i) fluxo horizontal e seção retangular ou quadrada; ii) fluxo em espiral (aerado); iii) fluxo em vórtice. As alternativas de gerenciamento do material removido (fase sólida) estão associadas tipicamente à secagem e posterior disposição final em aterros sanitários. A recuperação da areia removida para fins de preparo de concreto não estrutural ou reposição em leitos de secagem na própria ETE ainda é incipiente, mas pode se configurar como uma importante alternativa de gerenciamento deste subproduto a curto e médio prazo.

Há relatos esparsos na literatura associados à caracterização qualitativa dos resíduos removidos no tratamento preliminar, mas sabe-se que a quantidade e a composição do material retido na etapa de gradeamento dependem principalmente do espaçamento entre barras. Todavia, as características da bacia de contribuição da ETE influenciam no volume e qualidade do material removido, podendo-se elencar, entre outras (adaptado de WEF, 1994; WEF, 1998):

- O tamanho da área e o tipo de ocupação da bacia de contribuição;

- A configuração do sistema de coleta de esgoto: a presença de estações elevatórias diminui a quantidade de material retido no gradeamento, devido à remoção prévia antes do recalque (p. ex.: cestos em estações elevatórias de esgoto bruto e deposição de material no fundo do poço de sucção);

- Os hábitos e a educação sanitária da população atendida;

- Recebimento de caminhões limpa-fossa, efluente não doméstico, resíduos de outras ETEs (como escuma e lodo), resíduos de estações elevatórias (EE). É importante mencionar que o recebimento dessas contribuições acarreta um aumento na produção de lodo e na formação e acumulação de escuma nos reatores UASB, conforme apresentado na Parte 3 desta Coletânea de Notas Técnicas (NTs) (LOBATO et al., 2018).

O volume de sólidos retido no gradeamento varia usualmente entre 6 e 50 litros por $1.000 \mathrm{~m}^{3}$ de esgoto tratado (JORDÃO e PESSÔA, 2017). De acordo com uma caracterização quali-quantitativa efetuada por Borges (2014), em uma ETE de grande porte (Equivalente Populacional - EP $=258.000$ habitantes) no interior do estado de São Paulo, o material retido na etapa de gradeamento grosseiro (em termos de volume e massa) foi preponderantemente constituído por matéria orgânica putrescível (restos de alimentos, animais em decomposição, entre outros - $65 \%$ em volume), seguido de plástico ( $17 \%$ em volume), pedras ( $9 \%$ em volume), tecido ( $6 \%$ em volume) e papel (3\% em volume). Quanto à avaliação efetuada em relação aos resíduos retidos no gradeamento fino, uma configuração semelhante foi obtida. A composição do material retido apresentou variação sazonal significativa, indicando forte influência da precipitação no aumento da quantidade de pedras. Estas, por sua vez, referiam-se a placas de precipitados, contendo enxofre, cálcio e gorduras solidificadas, por exemplo.

Em relação à quantidade de areia presente no esgoto bruto, esta depende de diversos fatores, dentre eles: i) o tipo (sistema combinado ou separador) e as condições de conservação do sistema de coleta e transporte de esgoto; ii) características da drenagem pluvial da bacia de contribuição (coletores sujeitos a inundação tendem a receber maior carga de sedimentos através das tampas de poços de visita); iii) o tipo de ocupação da bacia de contribuição; e iv) o tipo de solo da bacia de contribuição e o grau de pavimentação das ruas. A quantidade de areia em sistemas separadores varia usualmente entre $4 \mathrm{e}$ 37 litros por $1.000 \mathrm{~m}^{3}$ de esgoto tratado (METCALF \& EDDY, 2003). 


\section{PRINCIPAIS CONFIGURAÇÕES PARA 0 TRATAMENTO PRELIMINAR}

As unidades que compõem o TP podem ser implantadas enterradas (Figura 1a), apoiadas ou elevadas (Figura 1b) em relação ao nível do terreno. As soluções enterradas podem facilitar o enclausuramento do TP, tal como demonstrado na Figura 1a para o desarenador e calha Parshall, todavia, podem implicar em maior dificuldade operacional associada à rotina de limpeza das unidades, além de, na maioria das vezes, demandarem uma EE dentro da ETE. Nesta configuração, o TP a montante da EE pode ter um importante papel na proteção dos conjuntos moto-bomba, mas não há como garantir que este aspecto compense a maior dificuldade com a operação das unidades enterradas. Cabe destacar que os aspectos associados à cobertura, exaustão e tratamento de odores no TP são abordados na Parte 4 desta Coletânea de NTs (BRANDT et al., 2018).

Por sua vez, a solução elevada pode demandar maior custo de implantação comparativamente à solução apoiada, embora possua a vantagem de permitir a descarga de fundo por gravidade dos desarenadores, o que pode implicar em simplificação ou eliminação de equipamentos eletromecânicos (p. ex.: parafuso classificador). Adicionalmente, a caçamba para coleta do material gradeado pode ser estrategicamente disposta próxima ao gradeamento, em nível inferior ao TP. Isso contribui para a melhoria das condições ergonômicas associadas à limpeza manual das grades de barra. Eventualmente, a etapa de gradeamento pode estar associada à elevatória de esgoto bruto, atentando-se para a necessidade de adoção de estrutura de controle das vazões afluentes (extravasor) para prevenir o afogamento das grades. Neste caso, entendendo-se que as grades sejam componentes da $\mathrm{EE}$, as unidades do TP se reduziriam à implantação do desarenador e, eventualmente, gradeamento fino e peneiramento. Em muitas situações, a elevação do TP elimina uma nova EE dentro da ETE, uma vez que o ganho de cota pode ser advindo do próprio emissário de recalque, contribuindo para que o perfil hidráulico seja integralmente a favor da gravidade.
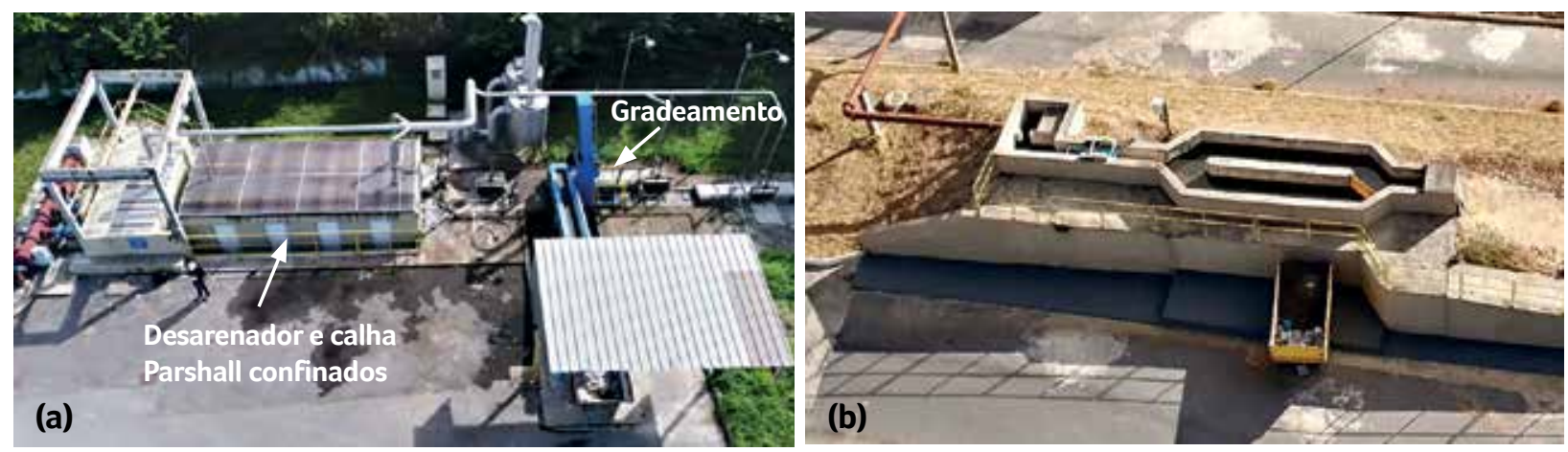

Figura 1 - Unidades do tratamento preliminar: a) Solução enterrada e enclausurada; b) Solução elevada. 
Os canais que conduzem às grades de barras e ao desarenador são tipicamente confeccionados em concreto armado, todavia, para ETEs de pequeno porte (Vazão - Q < 20 L.s ${ }^{-1}$ ou EP < 10.000 hab.), as dimensões de tais canais podem ser diminutas a ponto de dificultar a execução da obra em concreto, conforme abordado adiante, no item "Outros aspectos importantes de projeto, construção e operação".

\section{DIRETRIZES PARA PROJETO}

\subsection{Parâmetros e critérios de dimensionamento}

A lógica principal de dimensionamento das unidades do tratamento preliminar perpassa por assegurar velocidades de escoamento adequadas para a remoção de sólidos grosseiros, evitando problemas de obstrução, desgaste e travamento em equipamentos eletromecânicos, sensores e medidores de velocidade submersos. Todavia, deve-se assegurar que tais velocidades não impliquem na sedimentação da matéria orgânica particulada, o que propiciaria a geração de odores. As diretrizes de projeto para a etapa de tratamento preliminar encontram-se discriminadas na Norma Brasileira NBR 12.209 (ABNT, 2011).

Os principais parâmetros e critérios de dimensionamento das unidades componentes do tratamento preliminar são reportados na Tabela 1. Os diferentes arranjos recomendados para o TP referentes à escolha de grades e desarenadores são apresentados na Figura 2, em função do equivalente populacional (ou vazão afluente) da ETE. Ressalta-se que tais arranjos são oriundos da experiência operacional em ETEs em diversos estados brasileiros, notadamente nas regiões sul e sudeste, tendo sido extensamente discutidos junto a especialistas do setor de saneamento nacional.
Tabela 1 - Principais parâmetros e critérios de dimensionamento para as unidades do tratamento preliminar

\begin{tabular}{|c|c|}
\hline \multicolumn{2}{|c|}{ Gradeamento (grades de barras) } \\
\hline Parâmetro & Valor \\
\hline $\begin{array}{l}\text { Velocidade máxima através das } \\
\text { barras da grade para a vazão final }{ }^{\mathrm{a}}\end{array}$ & $1,20 m \cdot s^{-1}$ \\
\hline $\begin{array}{l}\text { Inclinação das barras em relação à } \\
\text { horizontal }\end{array}$ & $\begin{array}{c}45 \text { a } 60^{\circ} \text { - limpeza manual } \\
60 \text { a } 90^{\circ} \text { - limpeza mecanizada }\end{array}$ \\
\hline $\begin{array}{l}\text { Perda de carga mínima a ser } \\
\text { considerada (escoamento de } \\
\text { montante) }\end{array}$ & $\begin{array}{c}0,15 \text { m - limpeza manual } \\
\text { 0,10 m - limpeza mecanizada }\end{array}$ \\
\hline \multicolumn{2}{|c|}{ Desarenador } \\
\hline Parâmetro & Valor \\
\hline Velocidade de escoamento & 0,25 a $0,40 \mathrm{~m} \cdot \mathrm{s}^{-1}$ \\
\hline $\begin{array}{l}\text { Profundidade mínima para } \\
\text { acumulação de material } \\
\text { sedimentado }\end{array}$ & $0,20 \mathrm{~m}$ \\
\hline Taxa de escoamento superficial & 600 a $1.000 \mathrm{~m}^{3} \cdot \mathrm{m}^{-2} \cdot \mathrm{d}^{-1}$ \\
\hline
\end{tabular}

Nota: a vazão de dimensionamento das unidades do TP deve ser a vazão máxima afluente

${ }^{a}$ Os canais a montante e a jusante dos dispositivos de remoção de sólidos grosseiros devem garantir, pelo menos uma vez ao dia, desde o início da operação, uma velocidade igual ou superior a $0,40 \mathrm{~m} \cdot \mathrm{s}^{-1}$. A velocidade mínima de escoamento nestes canais deve ser idealmente superior a $0,30 \mathrm{~m} \cdot \mathrm{s}^{-1}$, a fim de evitar a deposição de areia nos canais.

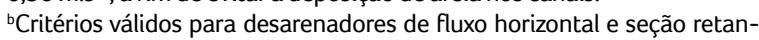
gular (tipo canal)

Fonte: adaptado de NBR 12.209 (ABNT, 2011)

\subsection{Arranjos recomendados para o tratamento preliminar}

Nota-se que na NBR 12.209 (ABNT, 2011) não há uma recomendação explícita sobre as possibilidades de utilização de diferentes tipos de grade (em termos do espaçamento entre barras e automação da limpeza), especialmente para ETEs de pequeno porte ( $\mathrm{Q}<20$ L.s s $^{-1}$ ou EP $<10.000$ hab.). No caso de estações cuja vazão máxima afluente em final de plano for igual ou superior a 100 L.s ${ }^{-1}$, as grades devem ser de limpeza mecanizada. Especificamente para sistemas de pequeno porte, a experiência operacional tem apontado positivamente para a utilização sequencial de duas grades finas de limpeza manual, com espaçamento livre entre as 
barras de 20 e $10 \mathrm{~mm}$, respectivamente (Figura 2). Cabe ressaltar que a opção por se utilizar grades de limpeza manual ou mecanizada para este porte de ETEs está a cargo do prestador de serviço, em vista do volume de material a ser retido ou das dificuldades operacionais (NBR 12.209 - ABNT, 2011).

Em se tratando de ETEs que empregam reatores UASB, é imprescindível a utilização de dispositivo de remoção de sólidos grosseiros com aberturas iguais ou inferiores a $12 \mathrm{~mm}$ para ETEs com vazão máxima até $100{\mathrm{~L} . \mathrm{s}^{-1}}^{-1}$ (NBR 12.209 - ABNT, 2011). De acordo com as experiências operacionais, a utilização de unidades de peneiramento estático ( 3 a $5 \mathrm{~mm}$ de abertura da malha) em ETEs de pequeno porte, pós-gradeamento, tem-se mostrado importante para evitar obstruções nas linhas de alimentação de reatores UASB (vertedores e tubulações), bem como em calhas coletoras de efluente tratado. Para estações cuja vazão máxima é superior a 100 L.s s $^{-1}$, é imprescindível a utilização de peneira com aberturas iguais ou inferiores a $6 \mathrm{~mm}$, segundo indicação da NBR 12.209 (ABNT, 2011). Neste caso, as experiências operacionais têm apontado o emprego preferencial de peneiras com abertura de malha de 3 ou $4 \mathrm{~mm}$.

A qualidade do lodo e da escuma descartados, em termos da presença de sólidos grosseiros, também se reflete na confiabilidade de operação dos sistemas de desaguamento mecanizado, reduzindo a necessidade de manutenção devido à obstrução de tubulações de alimentação de bombas e centrífugas, travamentos de rotores e estatores de bombas e de misturadores, rompimento de selos mecânicos, acúmulo de resíduos em tanques de equalização etc. Adicionalmente, uma remoção mais eficiente de sólidos grosseiros propicia a obtenção de um lodo de melhor qualidade estética, o que pode favorecer o uso agrícola, além de diminuir a formação de escuma no interior dos reatores anaeróbios.

Em relação aos desarenadores, para sistemas de pequeno porte (Q < 20 L.s $^{-1}$ ou EP $<10.000$ hab.) usualmente são adotadas as unidades de fluxo horizontal e seção retangular (tipo canal - ver Figura 1b), com velocidade constante garantida por meio de uma seção de controle implantada a jusante do desarenador (normalmente antes de uma calha Parshall) e remoção não mecanizada de areia. Uma opção bastante utilizada para sistemas de pequeno e médio porte $(Q$ < 100 L. $\mathrm{s}^{-1}$ ou EP < 50.000 hab.), sobretudo na região sul do país, refere-se ao desarenador de fluxo em vórtice (tipo ciclone), com remoção de areia por meio de air lift. Para sistemas de maior porte

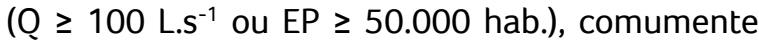
são adotadas as unidades de fluxo horizontal e seção quadrada em planta. Neste caso, a remoção da areia retida é efetuada por meio de braços raspadores e lavador de areia. Unidades de maior porte requerem atenção especial para assegurar uma distribuição uniforme da vazão afluente em toda a seção de escoamento do canal, além de uma atenta operação para identificar a ocorrência de fluxos preferenciais e/ou assoreamento em pontos específicos do canal, notadamente à montante da grade, especialmente no início de operação das ETEs.

Especificamente em relação aos desarenadores aerados (fluxo em espiral), embora sejam equipamentos de reconhecida eficiência para a remoção de areia, as esparsas experiências brasileiras reportadas na literatura indicam baixa eficiência destes equipamentos associada à remoção de óleos e graxas. Entre os possíveis motivos aventados, a diferença de viscosidade do líquido em função da temperatura pode ser um importante fator, visto que tais equipamentos, em sua maioria, são projetados para as condições de clima temperado. Todavia, há que se ressaltar experiências bem sucedidas com a operação de desarenadores aerados observadas pelos autores no estado do Rio de Janeiro. A possibilidade de remoção de óleos e graxas na etapa de tratamento preliminar pode ser interessante para a redução da formação de escuma em reatores UASB, que, especialmente nas ETEs de maior porte, representam um dos principais problemas operacionais. 


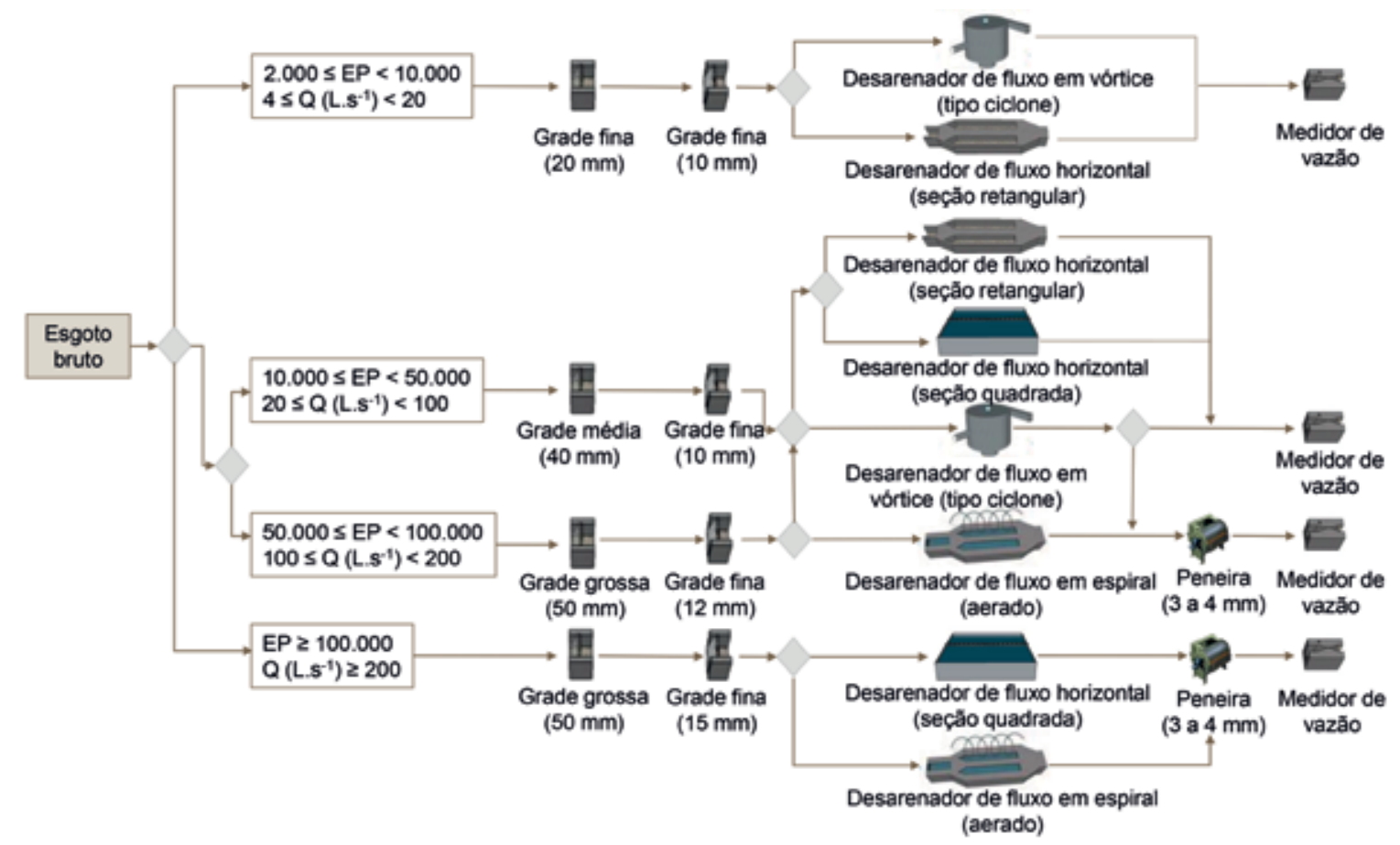

Figura 2 - Alternativas recomendadas para as unidades do tratamento preliminar de ETEs de diferentes portes. Nota: as equivalências entre Q e EP foram determinadas a partir de $Q_{\text {med }^{*}}$ O dimensionamento das unidades do TP deve ser realizado utilizando $Q_{\text {máx. }}$

Adicionalmente às alternativas recomendadas na Figura 2, devem ser verificadas as possibilidades de modulação e de redundância das unidades do TP, especificamente para ETEs de médio e grande porte ( $Q \geq 20$ L.s ${ }^{-1}$ ou EP $\geq 10.000$ hab.), conforme indicado na Tabela 2. Para ETEs de pe-

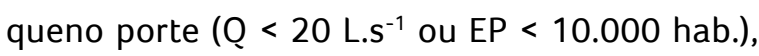
recomenda-se a implantação de um canal paralelo de desvio (by-pass) dotado de gradeamento fino (espaçamento entre barras igual a $20 \mathrm{~mm}$ ).

\subsection{Material retido nas unidades do tratamento preliminar}

De acordo com dados coletados junto a 24 ETEs na bacia hidrográfica do Rio das Velhas, no estado de Minas Gerais, o volume mediano de material retido nas unidades de gradeamento foi da ordem de 4,2 litros por $1.000 \mathrm{~m}^{3}$ de esgoto tratado (Figura 3) (2,5 a 8,0 L. $1.000 \mathrm{~m}^{-3}$ - percentis 25 e $75 \%$ dos dados), bem próximo ao limite inferior da faixa de valores reportada na literatura, entre 6 e 50 litros por 1.000 $\mathrm{m}^{3}$ de esgoto tratado (JORDÃO e PESSÔA, 2017). De certa forma, o pequeno volume de material retido nas grades identificado nesse levantamento causa estranheza, uma vez que, sabidamente, é grande a quantidade de detritos presentes nos esgotos gerados na maioria das cidades brasileiras. Fica a dúvida se a baixa retenção de material nas grades não é decorrente do elevado espaçamento entre barras, o que, em última instância, estaria contribuindo para a elevada presença de detritos no interior dos reatores (juntamente com a escuma e o lodo).

Para 23 destas ETEs investigadas, o volume mediano de material retido no desarenador foi da ordem de 40 litros por $1.000 \mathrm{~m}^{3}$ de esgoto tratado (Figura 3) ( 20 a 85 L. $1.000 \mathrm{~m}^{-3}$ - percentis 25 e $75 \%$ dos dados), ligeiramente superior ao limite máximo de 37 litros por $1.000 \mathrm{~m}^{3}$ de esgoto tratado, reportado por Metcalf \& Eddy (2003). Essa elevada quantidade de areia pode ser atribuída à ocorrência de infiltração na rede coletora e, principalmente, contribuição pluvial parasitária, que parece ser uma realidade em todo o território nacional. A título de informação complementar, dados verificados no litoral paulista indicam volumes de areia retidos da ordem de 60 litros por $1.000 \mathrm{~m}^{3}$ de esgoto tratado. 

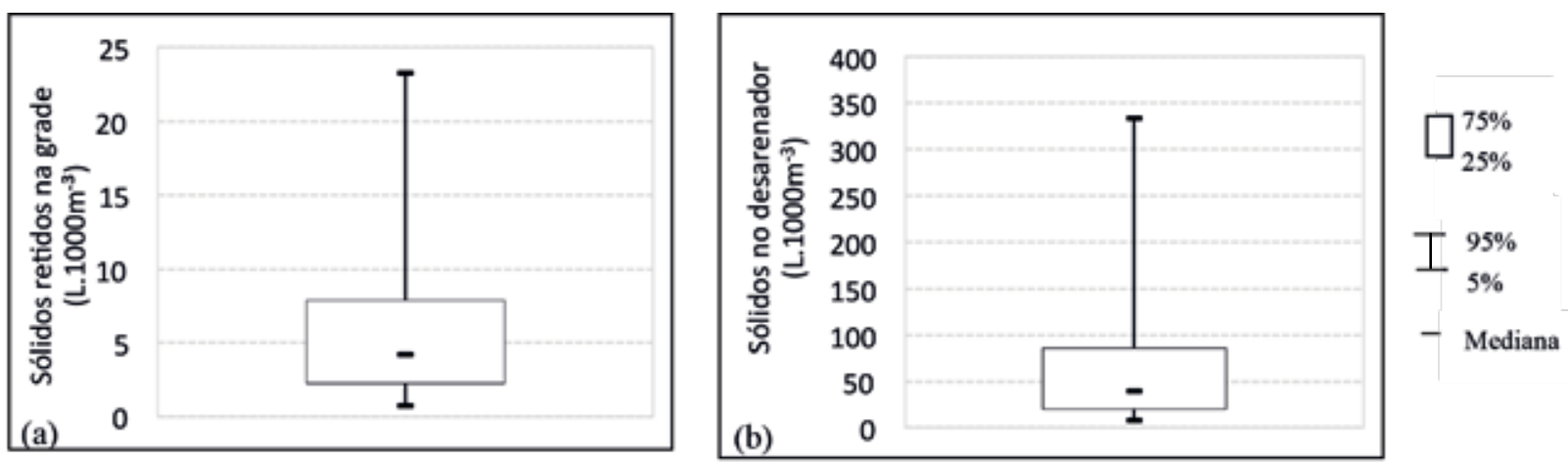

Figura 3 - Material retido nas unidades de tratamento preliminar de ETEs na bacia hidrográfica do Rio das Velhas.

(a) sólidos retidos na grade (L.1.000m-3); (b) sólidos retidos no desarenador (L.1.000m ${ }^{-3}$ ).

De fato os volumes de sólidos grosseiros e de areia retidos na etapa de tratamento preliminar dependem de uma série de fatores, tal como anteriormente caracterizado nessa NT, o que deve ser estritamente observado na etapa de projeto das ETEs.

\section{ASPECTOS RELACIONADOS A PROJETO, CONSTRUÇÃO, OPERAÇÃO E MANUTENÇÃO} Os principais aspectos a serem avaliados na análise de projetos das unidades que compõem o trata- mento preliminar são sintetizados na Tabela 2. Ao listá-los, buscou-se definir o grau de importância associado à observância de cada aspecto, de acordo com os seguintes critérios:

- Grau de importância médio - aspectos que, se não observados, podem comprometer a operação e manutenção adequada do sistema;

- Grau de importância alto - aspectos cuja observação é imprescindível para a boa operação e manutenção do sistema.

Tabela 2 - Principais aspectos a serem avaliados na análise de projetos das unidades que compõem o tratamento preliminar

\begin{tabular}{|c|c|c|}
\hline \multirow{2}{*}{ Aspectos gerais } & \multicolumn{2}{|c|}{$\begin{array}{l}\text { Grau de } \\
\text { importância }\end{array}$} \\
\hline & Alto & Médio \\
\hline $\begin{array}{l}\text { Consultar a unidade operacional e de manutenção eletromecânica anteriormente à definição da concepção/layout do TP (apoiado, } \\
\text { elevado, a montante da EE, equipamentos, possibilidade de recebimento de caminhão limpa fossa e efluentes não domésticos, forma de } \\
\text { limpeza e esgotamento das unidades, necessidade de controle de odor etc.). }\end{array}$ & $x$ & \\
\hline $\begin{array}{l}\text { Dimensionar as unidades usando a vazão máxima afluente e garantir as velocidades mínimas de escoamento, de forma a impedir a } \\
\text { deposição indesejada de sólidos orgânicos (SSV). }\end{array}$ & $\mathrm{x}$ & \\
\hline Justificar a escolha de tratamento preliminar manual ou mecanizado. & $\mathrm{X}$ & \\
\hline $\begin{array}{l}\text { Verificar o perfil hidráulico das unidades do TP. Devem ser consideradas as perdas de carga (canais, comportas e equipamentos) desde } \\
\text { o ponto de controle de escoamento (p.ex.: calha Parshall) até a unidade de gradeamento, para a definição das lâminas d'água (jusante e } \\
\text { montante de cada unidade). }\end{array}$ & $\mathrm{x}$ & \\
\hline $\begin{array}{l}\text { Prever dispositivo de extravasão de vazões afluentes superiores à capacidade de projeto da ETE. Notar que, em ETEs nas quais a EE de } \\
\text { chegada está localizada a jusante do TP e, onde há risco de interrupção do fornecimento de energia elétrica, dois extravasores devem ser } \\
\text { implantados, um antes do TP e outro associado ao poço de sucção da EE de chegada. Esta medida visa evitar o afogamento de unidades } \\
\text { implantadas a montante de elevatórias. }\end{array}$ & $x$ & \\
\hline $\begin{array}{l}\text { No canal de extravasão da ETE, prever a implantação de medidores de vazão que assegurem o registro da frequência e magnitude das } \\
\text { vazões afluentes derivadas para o curso d'água. }\end{array}$ & & $x$ \\
\hline $\begin{array}{l}\text { Prever válvula flap quando o extravasor for afogado, devendo a mesma ser instalada mais próxima ao tratamento preliminar, priorizando } \\
\text { o acesso para manutenção da válvula. }\end{array}$ & $\mathrm{x}$ & \\
\hline O by-pass a montante do tratamento preliminar deverá ser provido de dispositivo para esgotar a areia depositada na rede. & $\mathrm{X}$ & \\
\hline $\begin{array}{l}\text { Para ETEs de médio e grande porte ( } Q \geq 20 \mathrm{~L} . \mathrm{s}^{-1} \text { ou EP } \geq 10.000 \text { hab.), adotar redundância (duplicação) das unidades do TP (gradeamento, } \\
\text { desarenação e peneiramento). Avaliar alternativas de modulação para redução do investimento inicial, todavia, assegurar a manutenção } \\
\text { de velocidades mínimas, a fim de evitar a deposição indesejada de sólidos. }\end{array}$ & $x$ & \\
\hline
\end{tabular}




\begin{tabular}{|c|c|c|}
\hline \multirow{2}{*}{ Aspectos gerais } & \multicolumn{2}{|c|}{$\begin{array}{c}\text { Grau de } \\
\text { importância }\end{array}$} \\
\hline & Alto & Médio \\
\hline 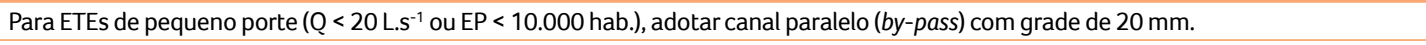 & $\mathrm{x}$ & \\
\hline $\begin{array}{l}\text { Verificar a possibilidade/viabilidade técnica e econômica de utilização de gradeamento mecanizado e/ou peneira estática para ETEs de } \\
\text { pequeno e médio porte ( } Q<100 \mathrm{~L} . \mathrm{s}^{-1} \text { ou EP < } 50.000 \text { hab.). }\end{array}$ & & $\mathrm{x}$ \\
\hline $\begin{array}{l}\text { Avaliar a possibilidade de implantação de gradeamento sequencial composto de grade grossa, média e fina, caso não seja adequado } \\
\text { utilizar o gradeamento mecanizado. }\end{array}$ & & $x$ \\
\hline $\begin{array}{l}\text { Prever sistema de coleta, armazenamento, transporte e disposição final dos resíduos sólidos retidos no TP considerando a rotina } \\
\text { operacional (frequência de remoção e destino) e incômodo à vizinhança (odores). }\end{array}$ & $\mathrm{x}$ & \\
\hline Prever comportas a montante e a jusante das unidades, que permitam a admissão, isolamento, limpeza e desvio (by-pass) dos esgotos. & $x$ & \\
\hline Nas especificações de comportas e equipamentos, considerar o uso de materiais resistentes à corrosão. & $x$ & \\
\hline $\begin{array}{l}\text { Para as estações elevatórias, observar a profundidade do poço de sucção, sendo preferencialmente limitada a } 8 \text { m. Em caso de poços } \\
\text { superiores a } 8 \text { m, deverão ser previstas condições de acesso para manutenção e limpeza (plataformas intermediárias, rampa, escada, } \\
\text { talha elétrica etc.) e guarda-corpo no entorno. Todavia, a depender do tipo de limpeza de grade, mesmo para profundidades inferiores a } 8 \\
\text { m devem ser garantidas condições adequadas de acesso e limpeza. }\end{array}$ & $\mathrm{x}$ & \\
\hline $\begin{array}{l}\text { Prever caçambas menores em ETEs de pequeno porte, a fim de não acumular resíduos por longos períodos de tempo, com a consequente } \\
\text { geração de odores. }\end{array}$ & & $\mathrm{x}$ \\
\hline $\begin{array}{l}\text { Avaliar a necessidade de prever dispositivos de cobertura para as caçambas de depósito de resíduos, em função das condições } \\
\text { pluviométricas locais e da necessidade de controle de odores. }\end{array}$ & $\mathrm{x}$ & \\
\hline Considerar asfalto e passeio cimentado no entorno das unidades no projeto paisagístico e de urbanização do tratamento preliminar. & $x$ & \\
\hline $\begin{array}{l}\text { Garantir acesso compatível com os veículos utilizados pela operação para a retirada das caçambas/containers, incluindo: inclinação } \\
\text { adequada das rampas de acesso; área de manobra suficiente e raios de curvas adequados para o trânsito de caminhões; base, sub-base e } \\
\text { pavimento compatível com o tráfego de veículos. }\end{array}$ & $\mathrm{x}$ & \\
\hline $\begin{array}{l}\text { Prever acesso adequado para os operadores executarem as atividades rotineiras e, também, de manutenção eletromecânica das } \\
\text { unidades (p.ex.: lubrificaçãa, retirada de motores, roscas etc.). }\end{array}$ & $\mathrm{x}$ & \\
\hline Considerar coleta e direcionamento do percolado das caçambas para o afluente à ETE. & $\mathrm{x}$ & \\
\hline $\begin{array}{l}\text { Em ETEs que recebam efluentes de caminhões limpa fossa, escuma e lodo de outras ETEs e EEEs, deve-se considerar a instalação de } \\
\text { unidade específica para recebimento e controle (p.ex.: tanque de homogeneização), atentando para o impacto na produção de lodo no } \\
\text { reator UASB (ver Nota Técnica 3 - Lobato et al., 2018). }\end{array}$ & $\mathrm{x}$ & \\
\hline $\begin{array}{l}\text { Garantir a compatibilização entre os equipamentos previstos em projeto e aqueles de fato adquiridos, para se evitar adequações na } \\
\text { estrutura civil e eletromecânica das unidades do tratamento preliminar, durante as fases de construção e operação. }\end{array}$ & $\mathrm{x}$ & \\
\hline Gradeamento & Alto & Médio \\
\hline $\begin{array}{l}\text { Para a estimativa de sólidos grosseiros e areia retidos, utilizar dados operacionais relacionados à realidade local (verificar as } \\
\text { características da bacia de esgotamento, como: ocupação e atividade econômica). }\end{array}$ & $\mathrm{x}$ & \\
\hline Em caso de unidades mecanizadas, prever canal paralelo com grade de limpeza manual, com mesmo espaçamento entre barras. & $\mathrm{x}$ & \\
\hline $\begin{array}{l}\text { O gradeamento deverá ser executado com barras de seção retangular. Não utilizar barras de seção circular ou barras horizontais para } \\
\text { auxílio na fixação das barras principais, pois dificultam a livre passagem do rastelo. }\end{array}$ & $\mathrm{x}$ & \\
\hline $\begin{array}{l}\text { Para tratamento preliminar implantado a jusante de estação elevatória, deverá ser previsto gradeamento grosseiro a montante da } \\
\text { elevatória (notar que o espaçamento entre barras deve ser inferior ao diâmetro do rotor da bomba, para evitar passagem de sólidos } \\
\text { grosseiros de maiores dimensões). Adicionalmente, deverá ser avaliada a possibilidade de implantação de gradeamento médio e fino a } \\
\text { montante da elevatória. }\end{array}$ & $\mathrm{x}$ & \\
\hline $\begin{array}{l}\text { Para ETEs com desaguamento mecanizado de lodo e/ou de escuma, prever no tratamento preliminar uma etapa de peneiramento com } \\
\text { malha de até } 6 \mathrm{~mm} \text { (preferencialmente } 3 \text { ou } 4 \mathrm{~mm} \text { ), visando assegurar a adequada operação e minimização de paralisaçães dessas } \\
\text { unidades (p. ex.: misturador de tanque de equalização, bombas de alimentação de equipamentos de desaguamento). }\end{array}$ & $\mathrm{x}$ & \\
\hline $\begin{array}{l}\text { Em ETEs de grande porte com gradeamento mecanizado, avaliar a possibilidade de utilização de dispositivos de compactação para os } \\
\text { resíduos removidos, objetivando reduzir o volume e a liberação de percolado em caçambas e containers, reduzir odores e melhorar as } \\
\text { características do material para disposição final. }\end{array}$ & & $\mathrm{x}$ \\
\hline Desarenador & Alto & Médio \\
\hline $\begin{array}{l}\text { Quando a largura do desarenador for inferior a } 30 \mathrm{~cm} \text {, avaliar e propor alternativas, como desarenador do tipo fluxo em vórtice ou } \\
\text { confecção de equipamento de limpeza sob medida, compatível com as menores dimensões do canal ou ainda a adoção de soluções pré- } \\
\text { fabricadas em materiais alternativos (p.ex.: fibra de vidro e polipropileno - PP). }\end{array}$ & & $x$ \\
\hline $\begin{array}{l}\text { Para desarenadores de limpeza manual, verificar a existência de rebaixo adequado para o acúmulo de areia em função da frequência de } \\
\text { limpeza adotada pela operação. }\end{array}$ & $\mathrm{x}$ & \\
\hline Onde a topografia permitir, adotar descarte de areia pelo fundo, de maneira a reduzir o gasto com caminhão limpa fossa. & & $x$ \\
\hline $\begin{array}{l}\text { Para os desarenadores mecanizados de seção quadrada, a moldagem da circunferência do raspador deve ser realizada dentro do } \\
\text { quadrado em que está inscrito (contemplando chanfros nos vértices), com uso do próprio braço raspador do equipamento. }\end{array}$ & $x$ & \\
\hline $\begin{array}{l}\text { Para os desarenadores de seção quadrada, garantir uma distribuiç̧ão uniforme da vazão ao longo da largura da unidade. Além de se } \\
\text { ter um dimensionamento hidráulico adequado no canal de acesso, deverá haver possibilidade de se regular a vazão em cada ponto de } \\
\text { entrada. }\end{array}$ & $x$ & \\
\hline $\begin{array}{l}\text { Para os desarenadores de seção quadrada, garantir a possibilidade de acesso para a limpeza do canal afluente, visto que, em algumas } \\
\text { situações, pode haver a deposição de areia nos extremos desse canal devido à ocorrência de velocidades inferiores às mínimas previstas } \\
\text { no projeto. }\end{array}$ & $x$ & \\
\hline $\begin{array}{l}\text { Para os desarenadores de seção quadrada, avaliar a possibilidade de prever descarga de fundo para o esgotamento das unidades, a fim } \\
\text { de possibilitar a limpeza e a manutenção do braço raspador e do dispositivo classificador. }\end{array}$ & $x$ & \\
\hline
\end{tabular}


Nota-se que a maioria dos aspectos anteriormente listados foram categorizados como de significância alta. Tal fato reflete a importância do tratamento preliminar para o adequado condicionamento dos esgotos preliminarmente à entrada nos reatores UASB. Em síntese, um adequado tratamento preliminar influenciará positivamente: i) na manutenção das estruturas de distribuição de vazão e calhas coletoras de efluente, evitando obstruções; ii) na redução da deposição/ acúmulo de areia no fundo de reatores UASB; iii) no gerenciamento do lodo, visto que será possível obter um sólido com menor conteúdo de detritos e areia, e de melhor qualidade estética; iv) no gerenciamento de escuma, sobretudo devido ao fato de que, quando não removidos adequadamente no tratamento preliminar, alguns materiais (p.ex.: plásticos e detritos leves em geral) tendem a flotar no interior do reator e acumular na parte superior do separador trifásico; v) na redução significativa de problemas corriqueiros na operação das unidades de processamento mecanizado de lodo e escuma, como paralisação por obstruções de tubulações, quebra e perda de rendimento de equipamentos por desgaste.

\subsection{Emissões odorantes no tratamento preliminar}

Nas situações em que os canais do TP não são confinados, o perfil hidráulico no projeto e implantação das unidades deve evitar a formação de turbulências, objetivando minimizar o desprendimento de gases odorantes e com potencial de corrosão. Quando os canais do TP são confinados, com exaustão dos gases, deve-se avaliar a possibilidade da chegada do esgoto ocorrer em regime turbulento (p. ex.: utilizando tubulações com descarga acima do NA máximo operacional), de modo a facilitar o desprendimento, a exaustão e o tratamento dos gases dissolvidos no esgoto afluente.
Adicionalmente, materiais resistentes à corrosão, bem como a proteção das estruturas de concreto em locais de sabida emissão de gases devem ser assegurados, tal como apontado na Parte 4 desta Coletânea de NTs (BRANDT et al., 2018).

A emissão de odores no tratamento preliminar em ETEs de pequeno porte também está associada ao acúmulo do material retirado nas grades, quando depositado em caçambas. Recomenda-se a utilização de caçambas de menor volume, para que o material ali disposto não fique armazenado por um longo período. Eventualmente, a aplicação de cal virgem para controlar a emissão de odores pode ser necessária (Figura 4a). Nestes casos, é necessário prever local adequado para armazenamento desses produtos na ETE. Em contrapartida,

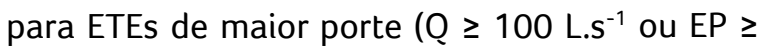
50.000 hab.), podem ser requeridas medidas de fechamento de caçambas que considerem materiais resistentes (p.ex.: dobradiças, fixação de lonas) e a observância à aspectos ergonômicos (p.ex.: peso). 0 acesso de caminhões (p.ex.: declividade de rampas, raios de curvas, capacidade suporte do pavimento, área de manobra) para a retirada de caçambas também deve ser considerado na etapa de projeto e construção da ETE.

Outro aspecto importante está associado à garantia das velocidades mínimas de escoamento nos canais a montante e a jusante do gradeamento e do desarenador, idealmente superiores a $0,30 \mathrm{~m} \cdot \mathrm{s}^{-1}$, para evitar a deposição indesejada de sólidos nessas estruturas, como exemplificado na Figura 4b. Atenção especial deve ser direcionada a possíveis mudanças de seção transversal no transcurso destes canais. $O$ eventual acúmulo de materiais nesses pontos implica na emissão de maus odores, associados à decomposição dos sólidos orgânicos indevidamente retidos, bem como pode comprometer o funcionamento de grades e comportas. 

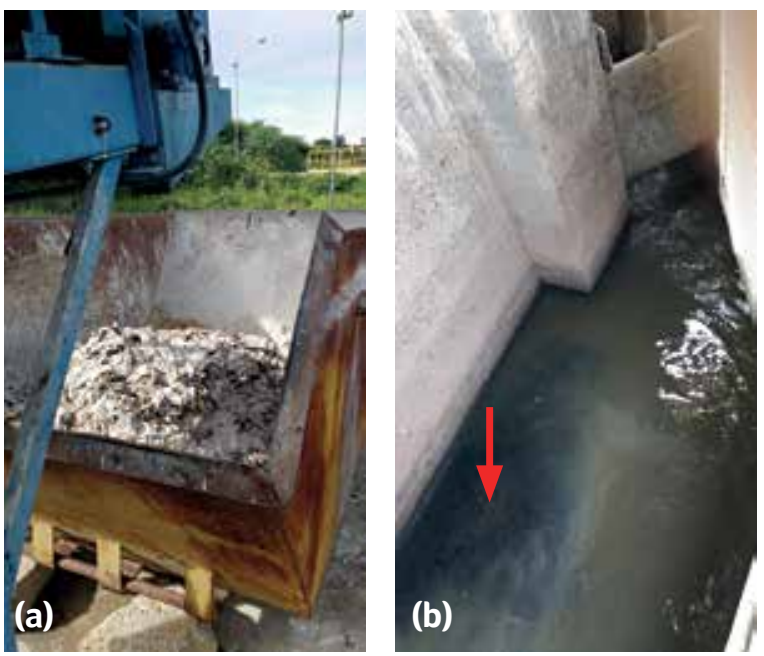

Figura 4 - (a) Manejo do material removido na etapa de gradeamento, com aplicação de cal; (b) Acúmulo de sólidos no canal afluente ao desarenador.

\subsection{Bombeamento e distribuição de vazão}

A etapa de bombeamento das vazões afluentes à ETE para o reator UASB é um ponto crucial para o adequado desempenho dos reatores anaeróbios. Nos casos em que há necessidade de recalque da vazão afluente à ETE para a alimentação dos reatores UASB, especialmente em estações

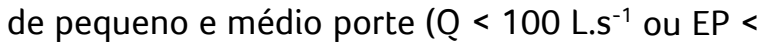
50.000 hab.), verifica-se que os projetos contemplam tipicamente apenas duas bombas, sendo uma para rodízio e reserva. Logo, os reatores são expostos a condições de sobrecarga hidráulica, devido ao bombeamento constante de uma vazão igual ou superior à vazão máxima para a qual foram projetados, culminando em eventos de queda na eficiência de retenção de sólidos e remoção de matéria orgânica.

Tal como previsto no item 6.4.2 da NBR 12.209, no caso de alimentação por estação elevatória, a vazão máxima de bombeamento não pode exceder mais que $25 \%$ da vazão máxima de esgoto afluente (ABNT, 2011). Neste caso, recomenda-se a utilização de bombas com variadores de velocidade (inversores de frequência) ou o mínimo de três bombas, sendo uma para rodízio e reserva. Adicionalmente, recomenda-se a instalação de um medidor de vazão após a estação elevatória, com o intuito de caracterizar o efetivo hidrograma de vazões afluente ao reator UASB. Tal medida reveste-se de importância, sobretudo quando da troca de equipamentos, em que bombas com diferentes pontos operacionais costumam ser instaladas.

Especificamente quanto às caixas de distribuição do esgoto afluente aos reatores UASB, é comum notar estruturas com o fundo plano e/ou com baixa inclinação (Figura 5a), o que propicia o acúmulo de areia e/ou detritos, especialmente quando da ocorrência de falhas no tratamento preliminar. Nesse sentido, recomenda-se a adoção de caixas com fundo inclinado (Figura 5b). Adicionalmente, estruturas confeccionadas em materiais que permitem melhor acabamento (p.ex.: fibra de vidro - Figuras 5 a e 5b), bem como o correto dimensionamento e verificação das lâminas d'água nos vertedores triangulares para as vazões máximas de bombeamento, são aspectos importantes para a garantia de uma distribuição uniforme de vazão para dentro dos compartimentos que alimentam os tubos de distribuição. Por sua vez, esses tubos conectados ao fundo das caixas de distribuição devem possuir diâmetro de $75 \mathrm{~mm}$, visto que, ao passo que garantem uma velocidade descendente adequada, são grandes o suficiente para evitarem frequentes obstruções (obviamente, quando se tem um funcionamento satisfatório do TP). Ressalta-se a necessidade de completa garantia da correta fixação dos tubos às estruturas de distribuição, uma vez que estes podem se soltar sob a laje sem que o operador perceba que o tubo está desconectado. Neste caso, o esgoto afluente adentraria o compartimento de decantação do reator UASB, ao invés de ser distribuído ao fundo da unidade. 

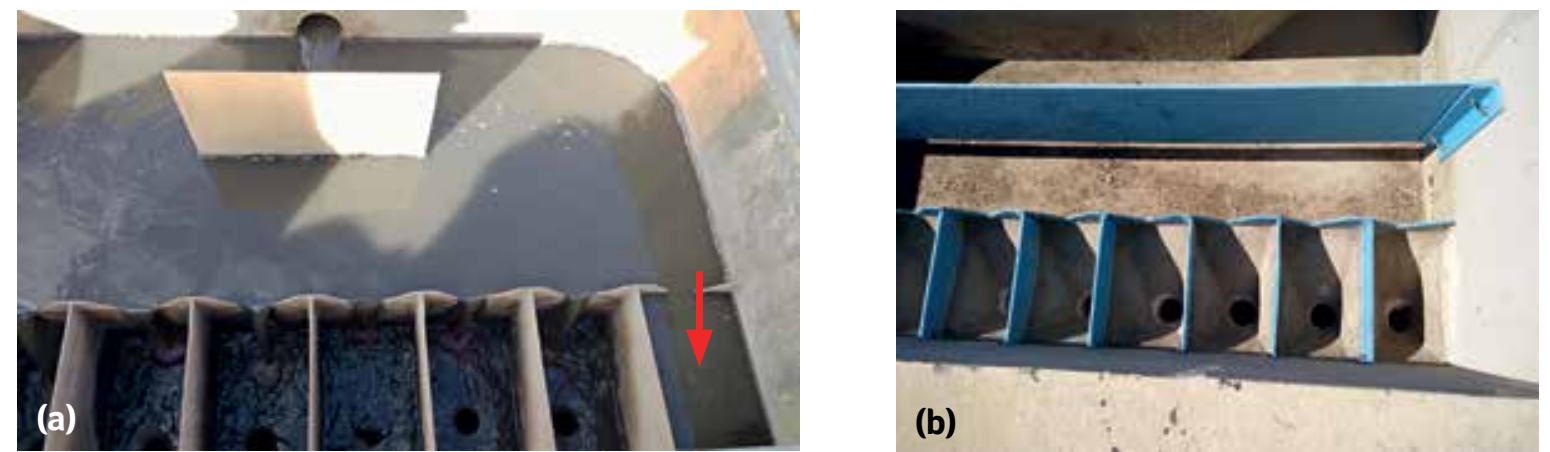

Figura 5 - Detalhes de compartimentos de distribuição de vazão afluente a reatores UASB: a) Caixa com fundo plano, com destaque para o entupimento de um tubo; b) Caixa com fundo inclinado.

\subsection{Outros aspectos importantes de projeto, construção e operação}

Especificamente para ETEs de pequeno porte (Q < 20 L.s ${ }^{-1}$ ou EP $<10.000$ hab.), as dimensões do tratamento preliminar, especialmente os canais afluente e efluente ao gradeamento e desarenador, tornam-se diminutas para atender às condições ideais de escoamento previstas na NBR 12.209 (ABNT, 2011). Logo, o emprego de estruturas de concreto armado moldado in loco pode não ser a solução ideal, em vista das dificuldades associadas à retirada das formas de concretagem e à garantia da espessura necessária ao cobrimento mínimo de armadura (5 cm - NBR 6.118 - ABNT, 2014). Neste caso, tal como mencionado anteriormente, soluções pré-moldadas em materiais alternativos podem ser uma interessante alternativa, a exemplo do plástico reforçado em fibra de vidro (PRFV) e do polipropileno.

A preocupação com critérios ergonômicos e de saúde e segurança no trabalho deve fazer parte do projeto e construção das unidades do TP, a exemplo da previsão de instalação de guarda-corpo e escadas de acesso (resistentes à corrosão), pontos de água de serviço, aberturas mínimas para passagem de operadores e ferramental adequado para as operações de limpeza e manutenção. A previsão de dispositivos de esgotamento dessas unidades também torna mais ágil e simples as operações de limpeza destas unidades.
É de fundamental importância que o projeto leve em consideração as especificidades dos equipamentos que serão efetivamente adquiridos $e$ implantados, tais como: perda de carga efetiva, necessidade de rebaixos, demanda de água para limpeza, descarga de drenos, apoio para roscas e grades, acesso para manutenção eletromecânica e limpezas etc. A compatibilização entre os equipamentos previstos em projeto e aqueles de fato adquiridos é crucial para se evitar adequações na estrutura civil e eletromecânica das unidades do tratamento preliminar, durante as fases de construção e operação, as quais podem representar custos significativos.

Finalmente, torna-se importante chamar a atenção para problemas construtivos recorrentes, tanto de obra como de instalação de equipamentos, tais como equipamentos instalados desnivelados (comportas, braços raspadores de desarenadores, classificadores de areia) e equipamentos que reduzem a seção do canal com paramentos laterais.

\section{AGRADECIMENTOS}

Os autores agradecem o apoio recebido do Conselho Nacional de Desenvolvimento Científico e Tecnológico - CNPq, da Coordenação de Aperfeiçoamento de Pessoal de Nível Superior - CAPES, da Fundação de Amparo à Pesquisa do Estado de 
Minas Gerais - FAPEMIG e do Instituto Nacional de Ciência e Tecnologia em Estações Sustentáveis de Tratamento de Esgoto - INCT ETEs Sustentáveis.

Este trabalho faz parte da série de publicações do INCT ETEs Sustentáveis.

\section{REFERÊNCIAS BIBLIOGRÁFICAS}

ABNT - Associação Brasileira de Normas Técnicas. NBR 12209: Elaboração de projetos hidráulico-sanitários de estações de tratamento de esgotos. $2^{a}$ ed. Rio de Janeiro, 2011.57 p.

ABNT - Associação Brasileira de Normas Técnicas. NBR 6118: Projeto de estruturas de concreto - Procedimento. $3^{\mathrm{a}}$ ed. Rio de Janeiro, 2014. $238 \mathrm{p}$.

BORGES, N. B. Aproveitamento dos resíduos gerados no tratamento preliminar de estações de tratamento de esgoto. 2014. 238 p. Tese (Doutorado em Ciências: Engenharia Hidráulica e Saneamento). Universidade de São Paulo, São Paulo, 2014.

BRANDT, E. M. F., SANTOS, J. M. B., SOUZA, C. L., POSSETTI, G. R. C., BRESSANI-RIBEIRO, T., CARVALHO-JÚNIOR, A. N., CHERNICHARO, C. A. L. Contribuição para o aprimoramento de projeto, construção e operação de reatores UASB aplicados ao tratamento de esgoto sanitário - Parte 4: Controle de corrosão e emissões odorantes. Revista DAE - edição especial, v. 66, n. 214, p. 56-72, 2018.
JORDÃO, E.P., PESSÔA, C.A. Tratamento de esgotos domésticos. $8^{a}$ edição. Rio de Janeiro, ABES, 2017.

MARCELIS, P. \& WESSELS, C. Recovery and valorisation of cellulose from sewage: the route to circularity. In: $12^{\text {th }}$ European Waste Water Management Conference, 2018, Manchester, UK. Anais.... Manchester, UK, 2018.

METCALF \& EDDY, Wastewater Engineering: Treatment and Reuse. $4^{\text {th }}$ ed. New York, NY: McGraw-Hill, 2003. 1819 p.

LOBATO, L. C. S., BRESSANI-RIBEIRO, T., SILVA, B. S., FLÓREZ, C. A. D., NEVES, P. N. P., CHERNICHARO, C. A. L. Contribuição para o aprimoramento de projeto, construção e operação de reatores UASB aplicados ao tratamento de esgoto sanitário - Parte 3: Gerenciamento de lodo e escuma. Revista DAE - edição especial, v. 66, n. 214, p. 30-55, 2018.

RUIKEN, C.J., BREUER, G., KLAVERSMA, E., SANTIAGO, T., VAN LOOSDRECHT, M. Sieving wastewater - Cellulose recovery, economic and energy evaluation. Water Research, v. 47, p. 43-48, 2013.

WEF - Water Environment Federation. Preliminary Treatment for Wastewater Facilities. Manual of Practice OM-2. Alexandria, VA. 1994. WEF - Water Environment Federation. Design of Municipal Wastewater Treatment Plants. Manual of Practice n. 8, ASCE Manual and Report on Engineering Practice n. 76. Alexandria, VA. 1998. 